\title{
Comparison of Syphilis Rapid Diagnostic Test to Rapid Plasma Reagin, Treponema pallidum Haemagglutination Assay and Fluorescent Treponemal Antibody-Absorption for Syphilis and Yaws Diagnostics
}

\author{
Astuti Giantini ${ }^{1}$, Dewi Wulandari ${ }^{1}$, Siskawati Suparmin ${ }^{2, *}$ \\ ${ }^{1}$ Clinical Pathology Department, Faculty of Medicine, Universitas Indonesia/Cipto Mangunkusumo Central General Hospital, \\ Jl. Salemba Raya No.6, Jakarta, Indonesia \\ ${ }^{2}$ Faculty of Medicine, Universitas Indonesia, Jl. Salemba Raya No.6, Jakarta, Indonesia \\ *Corresponding author. E-mail: siskawati.suparmin2@gmail.com
}

Received date: Nov 1, 2019; Revised date: Mar 20, 2020; Accepted date: Mar 27, 2020

\section{Abstract}

ACKGROUND: Syphilis and yaws are the treponemal infections which have become serious public health problems, and both are serologically indistinguishable. Developed serological tests for syphilis may also be used to diagnose yaws. In remote area, test modality with minimal requirements were needed. This study investigated the diagnostic value of syphilis rapid diagnostic test (RDT) in diagnosing syphilis and yaws.

METHODS: For syphilis diagnostic test, serum samples were obtained from patients of outpatient clinic in Dr. Cipto Mangunkusumo National Central General Hospital who were sent for rapid plasma reagin (RPR) and Treponema pallidum haemagglutination assay (TPHA) to clinical laboratory of the hospital. The serum samples were collected and stored at $-80^{\circ} \mathrm{C}$ until the day of testing for syphilis RDT and fluorescent treponemal antibody-absorption (FTA-Abs). For yaws diagnostic test, serum samples were obtained as a part of surveillance study of yaws among children 1-15 years old in West Halmahera. Venous blood samples were used for syphilis RDT and the sera were separated and were sent to Dr. Cipto Mangunkusumo National Central General Hospital for RPR, TPHA, and FTA-Abs tests.
RESULTS: For syphilis diagnostic test, among 156 samples, 39 samples were positive with syphilis RDT. The sensitivity of syphilis RDT was similar to RPR and TPHA (100.0\%), the specificity was same as TPHA (77.5\%), but lower than RPR (84.8\%) when compared to FTA-Abs IgM. The sensitivity of syphilis RDT was $62.5 \%$ and the specificity was $96.0 \%$ when compare to FTA-Abs IgG. For yaws diagnostic test, among 176 samples, 13 samples were positive with syphilis RDT. By using FTA-Abs IgM as gold standard for diagnosing yaws, the RDT have similar sensitivity (50.0\%) with RPR and TPHA and syphilis RDT have similar specificity to TPHA (93.1\%). If compared to FTA-Abs IgG, the sensitivity of syphilis RDT was $40.0 \%$ and the specificity was $98.0 \%$.

CONCLUSION: Syphilis RDT gives similar results with TPHA in syphilis and yaws cases. It may be used as a first line screening test latent or untreated syphilis and yaws because of good sensitivity. For yaws diagnosis Syphilis RDT, RPR, and TPHA have low sensitivity, however all those tests have an excellent agreement.

KEYWORDS: FTA-Abs, rapid diagnostic test, syphilis, yaws

Indones Biomed J. 2020; 12(2): 136-42

\section{Introduction}

Syphilis is one of the sexually transmitted infections (STIs) that may cause severe complications such as neurosyphilis and disability. Among pregnant women, untreated syphilis may cause several pregnancy complications (67\%) including abortion, or neonatal infection (congenital syphilis). Despite the relatively simple technology and cost-effective therapy available, syphilis is still a widespread public health problem 
in many parts of the world. Syphilis is still a major cause of perinatal morbidity and mortality in many countries. Therefore, the guideline for diagnosis of syphilis in primary health care based on clinical and serological examinations were included in the Indonesia National Guidelines for STI Treatment in 2011.(1)

Patients with symptoms and signs suggestive of syphilis (genital ulcer, skin rash) may be assessed and treated as syphilis. However, since most syphilis patients have no signs and symptoms, the diagnosis is based on the results of blood tests for antibody detection.(2) Serologic tests for syphilis including nontreponemal and treponemal tests. Wasserman reaction (WR), rapid plasma reagin (RPR), venereal disease research laboratory (VDRL), and toluidine red unheated serum test (TRUST) are among other non-treponemal test. The fluorescent treponemal antibody-absorption (FTA-Abs), Treponema pallidum haemagglutination assay (TPHA), Treponema pallidum passive particle agglutination assay (TPPA), enzyme immunoassay (EIA)-based anti treponemal tests (enzymelinked immunosorbent assay (ELISA), chemiluminescence) and the majority of commercially available point-of-care or rapid tests are included in group of treponemal tests. FTA-Abs has long been thought of as a gold standard for treponemal examination.(3) In remote areas, where laboratory facilities and trained personnel are limited, samples should be referred to referral facilities, and therefore the result cannot be obtained real time. Currently available rapid tests were designed and developed as a point-of-care test that can be performed outside of the laboratory and applicable for whole blood samples, including capillary blood from finger prick.(2) Syphilis RDT is a qualitative examination by detecting specific antibody to Treponema pallidum in serum, plasma, and whole blood using immunochromatography. No special equipment is needed, and the result can be obtain within 5 minutes.(4)

Yaws is the most common non-venereal treponemal infection that can cause disability. Yaws is transmitted by direct contact with the patient through the skin and open wounds. The causative organism is Treponema pallidum subspecies pertenue which has close proximity to Treponema pallidum subspecies pallidum that causes syphilis. The disease is differentiated by syphilis from the mode of transmission, age at the onset of disease, geographic distribution, and clinical signs.(5)

Yaws was still become a public health problem in Indonesia which requires attention of all parties with the goal of eradication of the disease in 2019.(6) Currently, Indonesia is the largest contributor of Yaws cases in Southeast Asia. Despite very low national prevalence of yaws, in 2009, 8,309 cases was found to spread in the eastern provinces of Indonesia, namely East Nusa Tenggara, Southeast Sulawesi, Maluku, Papua and West Papua.(7) Infected populations are generally poor communities in a tropical, warm, and humid climate area. Approximately $75-80 \%$ of infected people are children less than 15 years old and they were the main reservoir of yaws infections.(8)

In attempting eradication of yaws, the main strategy should be done is the intensification of case finding and reporting. In places where the case of yaws was found, immediate efforts to stop the transmission of yaws by mass drug delivery for prevention.(9) The World Health Organization has also launched the eradication campaign of yaws in 2020. To achieve this goal, rapid diagnostic tests (RDT) for yaws as a part of the community survey are required. Yaws is serologically indistinguishable from syphilis. Therefore, the development of high sensitivity and specificity syphilis RDT made it possible to evaluate its use to diagnose yaws. RDT development can improve access to serological diagnosis in remote areas where laboratory facilities are not available. In addition, rapid results can also be obtained in the presence of RDT.(10)

In this research, we studied the sensitivity and specificity test of solid phase immunochromatographic assay of syphilis RDT for diagnosis of yaws and syphilis.

\section{Methods}

\section{Syphilis Diagnostic Test}

The study of syphilis diagnostic test was conducted at Dr. Cipto Mangunkusumo National Central General Hospital in April 2018. This study has been approved by Ethical Committee of Faculty of Medicine University of Indonesia registry number 0274/UN.2.F1/ETIK/2018. The serum samples were obtained from patients in outpatient clinic which were sent for RPR and TPHA test in clinical laboratory of the hospital. The serum samples were collected and stored at $-80^{\circ} \mathrm{C}$ until the day of testing for syphilis RDT and FTA-Abs.

\section{Yaws Diagnostic Test}

For yaws diagnostic test, serum samples were obtained as a part of surveillance study of yaws among children 1-15 years old in West Halmahera, Ternate-North Maluku. The study was conducted in October 2017-May 2018. All 
subjects were recruited after written informed consent were given by their parents or caregiver. The study was including anamnesis, physical examination, and the vein blood collection for RDT, RPR, TPHA, and FTA-Abs test. syphilis RDT tests were done on site using whole blood samples. Subsequently, sera were obtained by centrifugation separation from whole blood. Further examination of RPR, TPHA, and FTA-Abs IgM and FTA-Abs IgG were performed at the Clinical Pathology Laboratory of Dr. Cipto Mangunkusumo National Central General Hospital, Jakarta. Children with fever $>38^{\circ} \mathrm{C}$ or suffering from liver disease and unable to give sufficient sample were excluded from this study. The results of RDT, RPR and TPHA then were compared to FTA-Abs as gold standard of syphilis diagnosis.

\section{Statistical Analysis}

The statistical test was performed using SPSS ver 20.0 program (IBM Coorporation, New York, USA). The agreement of syphilis RDT with RPR and TPHA were determined by kappa coefficient. We compare the sensitivity, specificity, positive predictive value (PPV), and negative predictive value (NPV) of syphilis RDT, RPR, and TPHA in reference to FTA-Abs as the gold standard. The sensitivity of syphilis RDT, RPR, and TPHA is the proportion of subjects with diseases/FTA-Abs positive who tested positive with syphilis RDT, RPR, or TPHA. The specificity of syphilis RDT, RPR, and TPHA is the proportion of subjects without diseases/FTA-Abs negative who tested negative with syphilis RDT, RPR, or TPHA. The PPV is the proportion of the subjects with positive syphilis RDT, RPR, or TPHA tests who have disease which were FTA-Abs positive. The NPV is the proportion of patients with negative syphilis RDT, RPR, or TPHA tests who do not have the disease which were FTA-Abs negative.

\section{Results}

\section{Syphilis Diagnostic Test}

Among 156 samples obtained for syphilis diagnostic test study, 39 samples were positive with syphilis RDT. The comparison of syphilis RDT with RPR, TPHA, FTA-Abs IgG and FTA-Abs IgM can be seen in Table 1. The kappa coefficient showed substantial agreement $(\kappa=0.76)$ between syphilis RDT and RPR. Agreement of syphilis RDT with TPHA was almost perfect with $\kappa=0.90$.(11) Comparison of RPR and TPHA results with FTA-Abs can be seen in Table 2 and Table 3.

The sensitivity of RPR was $100.0 \%$ when compared to FTA-Abs IgM and $48.2 \%$ when compared to FTA-Abs IgG. The specificity of RPR was $84.8 \%$ when compared to FTA-Abs IgM and $99.0 \%$ when compared to FTA-Abs IgG. The sensitivity of TPHA was $100.0 \%$ when compared to FTA-Abs IgM and $60.7 \%$ when compared to FTA-Abs IgG. The specificity of TPHA was $77.5 \%$ when compared to FTA-Abs IgM and $95.0 \%$ when compared to FTA-Abs IgG.

\section{Yaws Diagnostic Test}

There were 196 subjects participated for yaws diagnostic test study. Twenty subjects were excluded because the volume of serum sample were not enough for FTA-Abs test. There were 176 subjects who were included in the study, consisting of 13 subjects with positive test results and 163 subjects with negative results of syphilis RDT. For comparison of syphilis RDT with RPR, we found that three of 13 subjects with positive syphilis RDT had negative RPR results. All of 163 subjects with negative results of syphilis RDT also had negative RPR result. For comparison of syphilis RDT with TPHA, we found that there was 1 of 13 subjects has positive syphilis RDT result but negative

Table 1. Syphilis RDT compared to RPR, TPHA, FTA-Abs IgM and FTA-Abs IgG for syphilis diagnosis.

\begin{tabular}{|c|c|c|c|c|c|c|c|c|c|}
\hline \multirow{2}{*}{ Syphilis RDT } & \multicolumn{2}{|c|}{ RPR } & \multicolumn{2}{|c|}{ ТPHA } & \multicolumn{2}{|c|}{ FTA-Abs IgM } & \multicolumn{2}{|c|}{ FTA-Abs IgG } & \multirow{2}{*}{ Total } \\
\hline & Positive & Negative & Positive & Negative & Positive & Negative & Positive & Negative & \\
\hline Positive & 27 & 12 & 36 & 3 & 5 & 34 & 35 & 4 & 39 \\
\hline Negative & 1 & 116 & 3 & 114 & 0 & 117 & 21 & 96 & 117 \\
\hline \multirow[t]{5}{*}{ Total } & 28 & 128 & 39 & 117 & 5 & 151 & 56 & 100 & 156 \\
\hline & & & & & Sensitivity & $: 100.0 \%$ & Sensitivity & $: 62.5 \%$ & \\
\hline & & & & & Specificity & $: 77.5 \%$ & Specificity & $: 96.0 \%$ & \\
\hline & & & & & PPV & $: 12.8 \%$ & PPV & : $89.7 \%$ & \\
\hline & & & & & NPV & $: 100.0 \%$ & NPV & $: 82.1 \%$ & \\
\hline
\end{tabular}


Table 2. RPR compared to FTA-Abs IgM and FTA Abs-IgG for syphilis diagnosis.

\begin{tabular}{|c|c|c|c|c|c|}
\hline \multirow{2}{*}{ RPR } & \multicolumn{2}{|c|}{ FTA-Abs IgM } & \multicolumn{2}{|c|}{ FTA-Abs IgG } & \multirow{2}{*}{ Total } \\
\hline & Positive & Negative & Positive & Negative & \\
\hline Positive & 5 & 23 & 27 & 1 & 28 \\
\hline Negative & 0 & 128 & 29 & 99 & 128 \\
\hline \multirow[t]{5}{*}{ Total } & 5 & 151 & 56 & 100 & 156 \\
\hline & Sensitivity & $: 100.0 \%$ & Sensitivity & $: 48.2 \%$ & \\
\hline & Specificity & $: 84.8 \%$ & Specificity & : 99.0\% & \\
\hline & PPV & $: 17.9 \%$ & PPV & $: 96.4 \%$ & \\
\hline & NPV & $: 100.0 \%$ & NPV & $: 77.3 \%$ & \\
\hline
\end{tabular}

in TPHA. There was also 1 of 163 subjects with negative syphilis RDT but positive TPHA. Coefficient of kappa for syphilis RDT compared with RPR was 0.86 , and with TPHA was is 0.92 which indicates excellent agreement. (11) The comparison of syphilis RDT to RPR, TPHA, FTA-Abs IgM and FTA-Abs IgG for yaws diagnosis, can be seen in tables 4 . The results of RPR compared to gold standard FTA-Abs IgM dan FTA-Abs IgG can be seen in table 5 . The sensitivity of RPR was $50.0 \%$ when compared to FTA-Abs IgM and $32.0 \%$ when compared to FTA-Abs IgG. The specificity of RPR was $94.8 \%$ when compared to FTA-Abs IgM and $98.7 \%$ when compared to FTA-Abs IgG. Comparison of TPHA with FTA-Abs IgM, FTA-Abs IgG can be seen in table 6 . . The sensitivity of TPHA was $50.0 \%$ when compared to FTA-Abs IgM and $40.0 \%$ when compared to FTA-Abs IgG. The specificity of TPHA was 93.1\% when compared to FTA-Abs IgM and $98.0 \%$ when compared to FTA-Abs IgG.

\section{Discussion}

\section{Syphilis Diagnostic Test}

The use of syphilis RDT as screening tests mandate a high sensitivity. In this study, the sensitivity of syphilis RDT to
IgM FTA-Abs was $100.0 \%$. However, when compared to IgG FTA-Abs the sensitivity was as low as $62.5 \%$. Antibody responses to Treponema pallidum in infected animals and humans have been widely studied. Within 2 weeks after exposure, the anti-treponemal IgM is produced and followed by production of $\operatorname{IgG}$. Both $\operatorname{IgM}$ and $\operatorname{IgG}$ can be found at 3 days from the onset of lesions in primary syphilis. Antitreponemal $\operatorname{IgM}$ can be found in untreated acute syphilis and latent syphilis. In treated patients, IgM levels decrease rapidly and may disappear after 6-12 months, while IgG will persist for many years.(12,13)

Early serological diagnosis of syphilis is essential to initiate early treatment of syphilis. When the tests results are not available immediately, patient may be lost to follow up.(14) Seeing the need for syphilis RDT as a screening test of syphilis in untreated patients, syphilis RDT can be an option because it has a high sensitivity when compared to FTA-Abs IgM and it also gives immediate result. However, positive syphilis RDT results cannot stand alone as a syphilis diagnostic tool in new onset syphilis and untreated patients because the lack of the specificity.

Despite lower sensitivity when compared to FTAAbs IgG, syphilis RDT has a high specificity (96.0\%). Therefore, the positive syphilis RDT results may indicate prolonged course of syphilis, regardless the disease activity.

Table 3. TPHA compared to FTA-Abs IgM and FTA-Abs IgG for syphilis diagnosis.

\begin{tabular}{|c|c|c|c|c|c|}
\hline \multirow{2}{*}{ ТРНА } & \multicolumn{2}{|c|}{ FTA-Abs IgM } & \multicolumn{2}{|c|}{ FTA-Abs IgG } & \multirow{2}{*}{ Total } \\
\hline & Positive & Negative & Positive & Negative & \\
\hline Positive & 5 & 34 & 34 & 5 & 39 \\
\hline Negative & 0 & 117 & 22 & 95 & 117 \\
\hline \multirow[t]{5}{*}{ Total } & 5 & 151 & 56 & 100 & 156 \\
\hline & Sensitivity & $: 100.0 \%$ & Sensitivity & $: 60.7 \%$ & \\
\hline & Specificity & : $77.5 \%$ & Specificity & : $95.0 \%$ & \\
\hline & PPV & $: 12.8 \%$ & PPV & $: 87.2 \%$ & \\
\hline & NPV & $: 100.0 \%$ & NPV & $: 81.2 \%$ & \\
\hline
\end{tabular}


Table 4. Syphilis RDT compared to RPR, TPHA, FTA-Abs IgM and FTA-Abs IgG for yaws diagnosis.

\begin{tabular}{|c|c|c|c|c|c|c|c|c|c|}
\hline \multirow{2}{*}{ Syphilis RDT } & \multicolumn{2}{|c|}{ RPR } & \multicolumn{2}{|c|}{ TPHA } & \multicolumn{2}{|c|}{ FTA-Abs IgM } & \multicolumn{2}{|c|}{ FTA-Abs IgG } & \multirow{2}{*}{ Total } \\
\hline & Positive & Negative & Positive & Negative & Positive & Negative & Negative & Positive & \\
\hline Positive & 10 & 3 & 12 & 1 & 1 & 12 & 10 & 3 & 13 \\
\hline Negative & 0 & 163 & 1 & 162 & 1 & 162 & 15 & 148 & 163 \\
\hline \multirow[t]{5}{*}{ Total } & 10 & 166 & 13 & 163 & 2 & 174 & 25 & 151 & 176 \\
\hline & & & & & Sensitivity & : $50.0 \%$ & Sensitivity & $: 40.0 \%$ & \\
\hline & & & & & Specificity & : 93.1\% & Specificity & : $98.0 \%$ & \\
\hline & & & & & PPV & $: 7.7 \%$ & PPV & : $76.9 \%$ & \\
\hline & & & & & NPV & : 99.4\% & NPV & : $90.8 \%$ & \\
\hline
\end{tabular}

Hence, for establishing syphilis diagnosis syphilis RDT results must be combined with clinical data, ie the duration of symptoms and signs experienced by the patient and the history of treatment. In contrast, in patient with chronic or treated syphilis infections, syphilis RDT was not a good tool for diagnosis, as it has low sensitivity in patients with IgM$\mathrm{IgG}^{+}$FTA-Abs.

Syphilis RDT is a treponemal test, and therefore the results were incomparable with RPR results, a nontreponemal test. However the syphilis RDT results was comparable and no significant difference with TPHA results in this study. Syphilis RDT showed sensitivity, specificity, PPV, and NPV values similar to TPHA when compared with FTA-Abs IgM. Positive treponemal RDT result cannot differentiate new and old infections. To distinguish those conditions, a serial-quantitative nontreponemal test is required.(15)

This study is the first study in Dr. Cipto Mangunkusumo National Central General Hospital that uses FTA-Abs as a gold standard for syphilis diagnosis. Accurate of FTA-Abs readings require a good quality fluorescence microscope, experience personnel, good reagents, and standardized protocol.(3) In this study, serum sample was used and not included whole blood. The choice of specimen type is important as reported by previous study that reported lower sensitivities on whole blood specimens.(15)

\section{Yaws Diagnostic Test}

For yaws diagnosis, syphilis RDT has excellent agreement with RPR and TPHA which were a routine method done at Dr. Cipto Mangunkusumo National Central General Hospital for syphilis testing. Syphilis RDT also has the same sensitivity, specificity, PPV, and NPV values as TPHA when compared to the gold standard FTA-Abs IgM and FTA-Abs IgG for diagnosing yaws. The sensitivity of Syphilis RDT (40\%) when compared to the FTA-Abs IgG gold standard was also slightly better than RPR (32\%) .

Positive in syphilis RDT and TPHA but negative in RPR may be related to disease activity, as nontreponemal test reflect active disease more accurately. On the other hand, treponemal test usually remain positive after treatment.(16) Syphilis RDT is treponemal-based and cannot distinguish between past and current infection.(17) In this study, we did not record the clinical stage of disease in patient with positive test results.

No data were found from previous studies comparing the results of syphilis RDT examinations of FTA-Abs. Other studies comparing syphilis RDT results with RPR and TPHA as gold standard showed high sensitivity and specificity of syphilis RDT. Limitations of this study was the limited number of positive cases. Specimens used in this study were vein whole blood sample and serum, while the

Table 5. RPR compared to FTA-Abs IgM and FTA-Abs IgG for yaws diagnosis.

\begin{tabular}{lcccccc}
\hline \multirow{2}{*}{ RPR } & \multicolumn{2}{c}{ FTA-Abs IgM } & & \multicolumn{2}{c}{ FTA-Abs IgG } & \multirow{2}{*}{ Total } \\
\cline { 2 - 3 } Positive & Negative & & Positive & Negative & \\
\hline Negative & 1 & 9 & 8 & 2 & 10 \\
\hline Total & 1 & 165 & 7 & 149 & 166 \\
\hline \multirow{5}{*nnnnn}{} & 2 & 174 & 15 & 151 & 176 \\
& Sensitivity & $: 50.0 \%$ & & Sensitivity & $: 32.0 \%$ & \\
& Specificity & $: 94.8 \%$ & & Specificity & $: 98.7 \%$ & \\
& PPV & $: 10.0 \%$ & PPV & $: 80.0 \%$ & \\
& NPV & $: 99.4 \%$ & NPV & $: 89.8 \%$ &
\end{tabular}


Table 6. TPHA compared to FTA-Abs IgM and FTA-Abs IgG for yaws diagnosis.

\begin{tabular}{|c|c|c|c|c|c|}
\hline \multirow{2}{*}{ ТРНА } & \multicolumn{2}{|c|}{ FTA-Abs IgM } & \multicolumn{2}{|c|}{ FTA-Abs IgG } & \multirow{2}{*}{ Total } \\
\hline & Positive & Negative & Negative & Positive & \\
\hline Positive & 1 & 12 & 10 & 3 & 13 \\
\hline Negative & 1 & 162 & 15 & 148 & 163 \\
\hline \multirow[t]{5}{*}{ Total } & 2 & 174 & 25 & 151 & 176 \\
\hline & Sensitivity & : $50.0 \%$ & Sensitivity & $: 40.0 \%$ & \\
\hline & Specificity & $: 93.1 \%$ & Specificity & $: 98.0 \%$ & \\
\hline & PPV & $: 7.7 \%$ & PPV & : $76.9 \%$ & \\
\hline & NPV & : 99.4\% & NPV & $: 90.8 \%$ & \\
\hline
\end{tabular}

manufacturer claimed syphilis RDT test may also use other types of samples including serum, plasma, and capillary whole blood.(18)

The sensitivity of syphilis RDT, RPR and TPHA for diagnosing yaws was lower than for diagnosing syphilis. It is similar with previous study which found that only 17 from 33 samples with reactive FTA-Abs also has reactive RPR results (51.5\%) in yaws patient serum.(19) Other previous study, found that from 661 children in region of hypoendemic yaws, there were 261 children with reactive FTA-Abs, but only 139 children have positive TPHA.(20) We did not found previous study which compare syphilis treponemal RDT with FTA-Abs for a comparison. This result seems contradicted with the theory that yaws is serologically indistinguishable with syphilis. We need further study to confirm it because of the limitation of this study which only has few samples with positive FTA-Abs results.

\section{Conclusion}

Syphilis RDT gives similar results to TPHA as diagnostic tool for syphilis and yaws. Syphilis RDT has good sensitivity for syphilis diagnosis if compared to FTA-Abs $\operatorname{IgM}$, however the sensitivity is lower when compared to FTA-Abs IgG. Therefore, it can be used as a screening test in early-stage syphilis or in untreated syphilis. Positive results of syphilis RDT require further examinations to confirm the diagnosis of syphilis and yaws due to lack of specificity.

\section{Acknowledgements}

This research was funded by PT Standard Biosensor Indonesia.

\section{References}

1. Daili SF, Indriatmi W, Wiweko SN, Dewi H, Tanudjaya F, Wignall $\mathrm{S}$, et al. Pedoman Tata Laksana Sifilis Untuk Pengendalian Sifilis Di Layanan Kesehatan Dasar. Jakarta: Kementerian Kesehatan Republik Indonesia Direktorat Jenderal Pengendalian Penyakit dan Penyehatan Lingkungan; 2013.

2. World Health Organization. The Use of Rapid Syphilis Test Switzerland: World Health Organization; 2006.

3. Ballard R, Hook III EW. Syphilis. In: Unemo M, Ballard R, Ison C, Lewis D, Ndowa F, Peeling R, editors. Laboratory diagnosis of sexually transmitted infections, including human immunodeficiency virus. Geneva: World Health Organization; 2013. p.107-30.

4. SD BIOSENSOR [Internet]. STANDARD Q Syphilis Ab [cited 2018 Mar 21]. Available from: http://en.sdbiosensor.com/xe/ product $/ 2628$ ? category $=2309$.

5. Marrouche N, Ghosn SH. Endemic (Nonvenereal) Treponematoses. In: Goldsmith LA, Katz SI, Gilchrest BA, Paller AS, Leffell DJ, Wolff C, editors. Fitzpatrick's Dermatology in General Medicine. 8th ed. New York: McGraw-Hill; 2012. p.2493-500.

6. Moeloek NF. Keputusan Menteri Kesehatan Republik Indonesia NOMOR HK.01.07/MENKES/496/2017 Tentang Daerah Endemis Frambusia. Jakarta: Kementrian Kesehatan RI; 2017.

7. Kementerian Kesehatan Republik Indonesia [Internet]. Kusta dan Frambusia Penyakit Terabaikan [updated 2010; cited 2018 Mar 21]. Available from: http://www.depkes.go.id/article/print/1188/kustadan-frambusia-penyakit-terabaikan.html.

8. World Health Organization [Internet]. Yaws [cited 2018 Mar 21] Available from: http://who.int/mediacentre/facsheets/fs316/en/.

9. Kementerian Kesehatan RI. Peraturan Menteri Kesehatan Republik Indonesia Nomor 8 Tahun 2017 Tentang Eradikasi Frambusia. Jakarta: Kementrian Kesehatan RI; 2017.

10. Marks M, Goncalves A, Vahi V, Sokana O, Puiahi E, Zhang Z. Evaluation of a rapid diagnostic test for yaws infection in a community surveillance setting. PLoS Negl Trop Dis. 2014 Sep 11; 8: e3156. doi: 10.1371/journal.pntd.0003156.

11. Watson PF, Petrie A. Method agreement analysis: A review of correct methodology. Theriogenology. 2010; 73: 1167-79.

12. Seña AC, White BL, Sparling PF. Novel Treponema pallidum serologic tests: a paradigm shift in syphilis screening for the $21 \mathrm{st}$ Century. Clin Infect Dis. 2010; 51: 700-8.

13. Braun-Falco O, Plewig G, Wolff H, Burgdoff W. Dermatology. 2nd ed. Verlag: Springer; 1965. 
14. Castro R, Lopes A, da Luz Martins Pereira F. Evaluation of an immunochromatographic point-of-care test for the simultaneous detection of nontreponemal and treponemal antibodies in patient with syphilis. Sex Transm Dis. 2014; 41: 467-9.

15. Morshed M, Singh AE. Recent trends in the serologic diagnosis of syphilis. Clin Vaccine Immunol. 2015; 22: 137-47.

16. Marks M, Lebari D, Solomon AW, Higgins SP. Yaws. Int J STD AIDS. 2014; 26: 696-703.

17. World Health Organization [Internet]. Yaws [cited 2018 Jul 13]. Available from: https://www.who.int/en/news-room/fact-sheets/ detail/yaws.

18. Podgorski T, Bartkowiak U, Pawlak M. Comparison of hematological parameters of venous and capillary blood in athletes. Trends Sports Sci. 2014; 1: 39-45.

19. Hopkins D, Florez D. Comparison of RPR "teardrop" card test, VDRL, and FTA-Abs tst results on sera from persons with suspected yaws in Colombia. Br J Vener Dis. 1977; 53: 218-20.

20. Menke H, Veldkamp J, Brunings E, Niemel P, Notowicz A, Stolz E. Comparison of cardiolipin and treponemal tests in serodiagnosis of yaws. Br J Vener Dis. 1979; 55: 102-4. 